\title{
Wave-Induced Sediment Motion Beyond the Surf Zone: Case Study of Lubiatowo (Poland)
}

\author{
Grzegorz R. Cerkowniak, Rafał Ostrowski, Magdalena Stella \\ Institute of Hydro-Engineering, Polish Academy of Sciences, ul. Kościerska 7, 80-328 Gdańsk, Poland, \\ e-mails: grcerkowniak@ibwpan.gda.pl,rafal.o@ibwpan.gda.pl,m.stella@ibwpan.gda.pl
}

(Received April 03, 2015; revised June 29, 2015)

\begin{abstract}
The paper presents results of field and theoretical investigations of a natural sandy shore located near the IBW PAN Coastal Research Station in Lubiatowo (Poland, the south Baltic Sea). The study site displays multi-bar cross-shore profiles that intensively dissipate wave energy, mostly by breaking. The main field data comprise offshore wave parameters and three cross-shore bathymetric profiles. Waveinduced nearbed velocities and bed shear stresses are theoretically modelled for weak, moderate, strong and extreme storm conditions to determine sediment motion regimes at various locations on the seaward boundary of the surf zone. The paper contains a discussion on the depth of closure concept, according to which the offshore range of sea bottom changes can be determined by the extreme seasonal deep-water wave parameters.
\end{abstract}

Key words: cross-shore seabed profile, offshore wave climate, wave transformation, nearbed flow velocities, bed shear stresses, sediment motion, depth of closure

\section{Introduction}

The nearbed motion of water in the coastal zone is basically dominated by wave-induced oscillatory flows and wave-driven currents (directed along the shore and perpendicularly to the shore, including return flows and rip currents). Such a situation is characteristic of the nearshore regions in which wave energy dissipation takes place. In the zone of wave transformation, particularly in the surf zone, the above hydrodynamic impacts cause an intensive motion of sea bottom sediments. Here, a significant spatial variability of sediment transport rates is a direct cause of distinct accumulative and erosive processes occurring on the seabed. Further from the shore, at large depths where the nearbed wave-induced water motion is much less intensive and where wave-driven currents do not occur, sediment transport rates considerably decrease, and the seabed changes become weak. At such locations, the motion of water (and consequently sediment) in the nearbed layer can be related to currents typically occurring in the open sea, for instance, drift currents. In tidal seas, e.g. in the North Sea, the occurrence and movement of large sandy bed forms at depths of 20-30 m, 
called sand waves or sand banks, are closely associated with tidal phenomena, see Carbajal \& Montaño (2001) and Hulscher \& van den Brink (2001).

A so-called depth of closure $\left(h_{c}\right)$ is conventionally assumed to be a seaward boundary of influence of extreme annual waves on the seabed. At the location of the depth of closure, these waves do not cause intensive sediment transport. The corresponding extreme wave conditions are most often represented by the "effective" significant wave height $\left(H_{e}\right)$, as that is exceeded only 12 hours per year, or $0.137 \%$ of the time. Simple formulas derived by Birkemeier (1985), or earlier by Hallermeier $(1978,1981)$, for the assessment of the depth of closure $h_{c}$ from the effective significant wave height $\left(H_{e}\right)$ and period $\left(T_{e}\right)$, are discussed e.g. by Dean (2002).

Obviously, the depth of closure $h_{c}$ can be determined directly from bathymetric changes if only sufficient data are available. First, one ought to assume the maximum range of the sea bottom level changes $\Delta h$ below which the seabed can be treated as inactive. The span $\Delta h$ is mainly dependent on the reliability and accuracy of the bathymetric data.

The classical definition of the depth of closure $h_{c}$ can be generalized for shorter or longer time periods. The longer the time domain (single storm, season, year, decade), the greater the depth of closure $h_{c}$. In long time scales, the depth of closure $h_{c}$ occurs far from the shoreline, in regions where seabed changes are usually very small. In such cases, the quantity $\Delta h$ is assumed to be as small as $0.06-0.15 \mathrm{~m}$ only. For shorter time scales, higher ranges of this quantity are allowed, namely $\Delta h=0.2-0.3 \mathrm{~m}$, see Capobianco et al (1997), Nicholls et al (1996) and Nicholls \& Birkemeier (1997).

In the investigations carried out for a reflective (i.e. wave-energy reflecting) single-bar Atlantic shore at the Duck Point Field Research Facility (USA), Capobianco et al (1997) and Nicholls \& Birkemeier (1997), considering time periods of several years, assumed $\Delta h=0.1-0.3 \mathrm{~m}$. For such cases, depth of closure values $\left(h_{c}\right)$ were found to be about $8 \mathrm{~m}$. The conventional one-year depths of closure amounted to $h_{c}=5 \mathrm{~m}, h_{c}=4.5 \mathrm{~m}$ and $h_{c}=4 \mathrm{~m}$ for $\Delta h=0.1 \mathrm{~m}, \Delta h=0.2 \mathrm{~m}$ and $\Delta h=0.3 \mathrm{~m}$, respectively.

The first studies devoted to the depth of closure in various time scales at a dissipative (i.e. wave-energy dissipating) multi-bar south Baltic shore were carried out at the Coastal Research Station (CRS) in Lubiatowo, Poland, see Różyński et al (1998). Those investigations yielded the values of $h_{c}$ in the range from $5 \mathrm{~m}$ to $10 \mathrm{~m}$. Obviously, low values of $h_{c}$ were obtained for short time scales (months) and high $\Delta h$ values (e.g. $\Delta h=0.3 \mathrm{~m}$ ), whereas high values of $h_{c}$ were associated with longer periods (years) and small $\Delta h$ values (below $0.2 \mathrm{~m}$ ). The longest time period analysed (1987-1996) was similar to the longest periods considered for the Duck Point site by Nichols et al (1996), Nicholls \& Birkemeier (1997) and Beavers et al (1999).

The results of recent research on the depth of closure at CRS Lubiatowo were presented by Cerkowniak et al (2015), who obtained actual values of $h_{c}$ (determined from bathymetric surveys) greater than the ones calculated using parameters of the effective significant wave height. As pointed out e.g. by Dean (2002), semi-empirical formulas 
for determining the depth of closure $h_{c}$ have been derived with the assumption that the bed shear stress generated by the nearbed wave-induced oscillatory flow is the driving force for sediment transport. The conclusions of Cerkowniak et al (2015) have given rise to a hypothesis concerning an important role of currents typically occurring beyond the surf zone of the non-tidal sea and interacting with wave-induced oscillatory flows. First, however, one should find the offshore boundaries at which extreme waves generate bed shear stresses sufficient to cause intensive sediment transport and, consequently, distinct sea bottom evolution without the contribution of any non-tidal "open sea" currents. The present study tackles this issue by the theoretical modelling of nearbed flow velocities and bottom shear stresses induced by extreme waves of various duration in the average year.

\section{Study Site and Data}

The measurements were carried out near CRS Lubiatowo, operated by the Institute of Hydro-Engineering of the Polish Academy of Sciences (IBW PAN). The study area of CRS Lubiatowo is situated about $70 \mathrm{~km} \mathrm{NW}$ of Gdańsk (see Figure 1), with a laboratory building at the coordinates $54^{\circ} 48^{\prime} 42.0^{\prime \prime} \mathrm{N}$ and $17^{\circ} 50^{\prime} 25.6^{\prime \prime} \mathrm{E}$. It is a typical south Baltic sandy coast. Field surveys conducted at Lubiatowo comprise coastal hydrodynamics, lithodynamics and morphodynamics. For the needs of the present study, deep-water wave buoy data were used, as well as three bathymetric profiles measured in 2004 and 2011, obtained from the Maritime Office in Gdynia. Bathymetric data collected by IBW PAN were used indirectly, via the results of investigations published by Cerkowniak et al (2015).

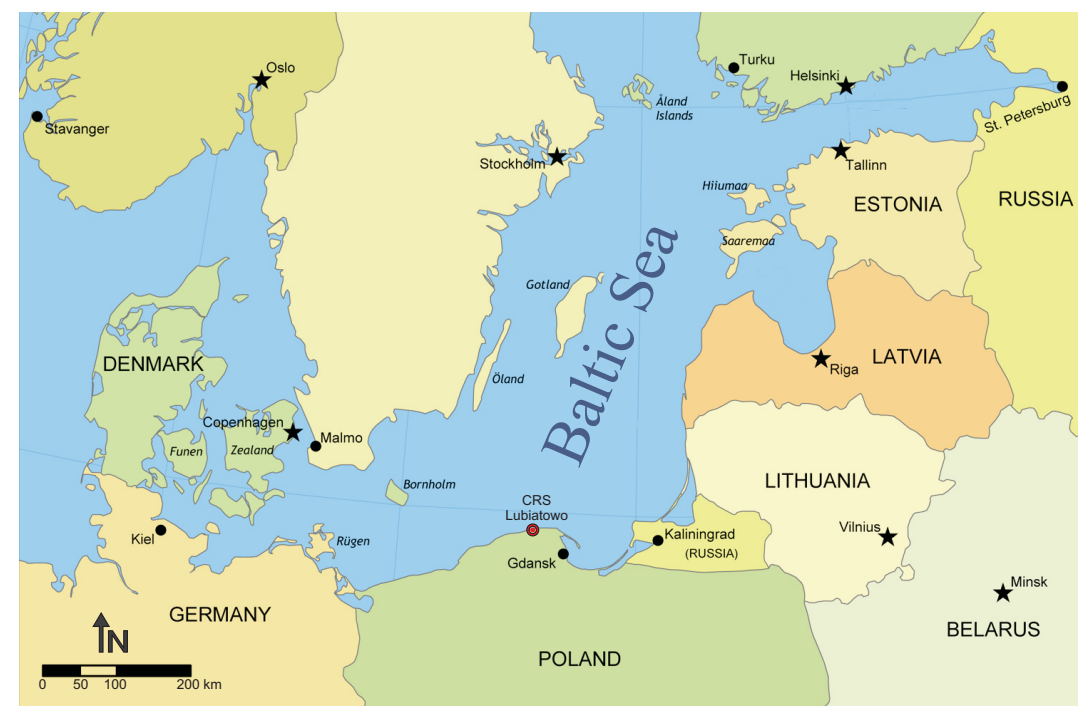

Fig. 1. Location of CRS Lubiatowo on the Baltic coast 
The sea shore near Lubiatowo is mildly sloped (with an inclination of 1-2\%) and consists of quartz sand having the median grain diameter $d_{50}=0.22 \mathrm{~mm}$. Cross-shore bathymetric profiles display 3-4 stable bars and an additional, ephemeral one occurring close to the shoreline. Such a multi-bar profile of the sea bottom is favourable to gradual wave energy dissipation, taking place within multiple wave breaking, see Pruszak et al (2008). As a result, only a small amount of wave energy reaches the direct vicinity of the shoreline.

As part of the operation of CRS Lubiatowo, bathymetric surveys are carried out in a longshore span of $2600 \mathrm{~m}$ and reach distances of 800-1000 $\mathrm{m}$ from the shoreline (sometimes a little more). Since the 1990s, these measurements have been conducted by means of an echo sounder installed on a GPS-positioned boat along 27 cross-shore profiles organised in two groups. In each group, the profiles are mutually parallel and spaced by $100 \mathrm{~m}$ from each other.

The frequency of bathymetric surveys and their seaward range depend on weather conditions and research needs, variable from one year to another. Therefore, bathymetric data have been collected rather irregularly. Some bathymetric profiles extend to a depth of no more than 5-6 m, thus covering the nearshore zone only. Those data concern the seabed that is very dynamic in short time scales, even under moderate wave conditions. Such bathymetric information is useless for the needs of the present study.

Under the Act of Parliament of the Republic of Poland (28 March 2003) on the establishment of a long-term "Coastal Protection Programme", periodic bathymetric monitoring has been carried out along the entire Polish coast. In the Lubiatowo region, measurements were carried out in 2004 and 2011 by the Maritime Office in Gdynia along transects perpendicular to the shoreline, spaced by $500 \mathrm{~m}$ from each other. For the purpose of the present study, the transects at KM 163.0, KM 163.5 and KM 164.0 were selected. The location of the transects refers to a longshore coordinate system used by the Maritime Office in Gdynia (KM 0.0 stands for the Polish eastern border). The transects at KM 163.5 and KM 164 lie within the longshore span of the bathymetric surveys conducted at CRS Lubiatowo and almost correspond (with an accuracy to several metres) to the IBW PAN cross-shore bathymetric profiles, whereas the transect at KM 163 is located in the adjacent eastern longshore segment. All of the profiles examined in the present study (KM 163.0, 163.5 and 164.0) stretch about $2000 \mathrm{~m}$ offshore and almost all of them reach a depth of at least $16 \mathrm{~m}$. The profiles are plotted in Figures 2-4.

Investigations of the hydrodynamics of a multi-bar coastal zone require knowledge of deep-water wave parameters, which constitute the input data for theoretical considerations (including mathematical modelling) of wave transformation, wave-driven currents and sediment transport. Since the 1990s, the offshore wave parameters at CRS Lubiatowo have been monitored by means of directional wave buoys ("Directional Waverider Buoys") produced by the Dutch company Datawell BV, namely Waverider Mk. II and DWR-7 Mk. III. The schedules of field investigations at the site 


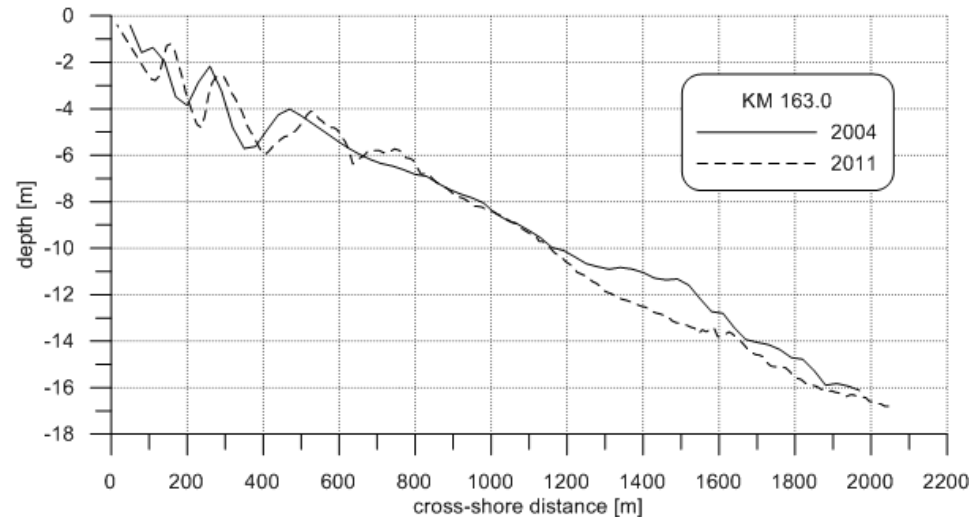

Fig. 2. Cross-shore profile at KM 163.0 in 2004 and in 2011

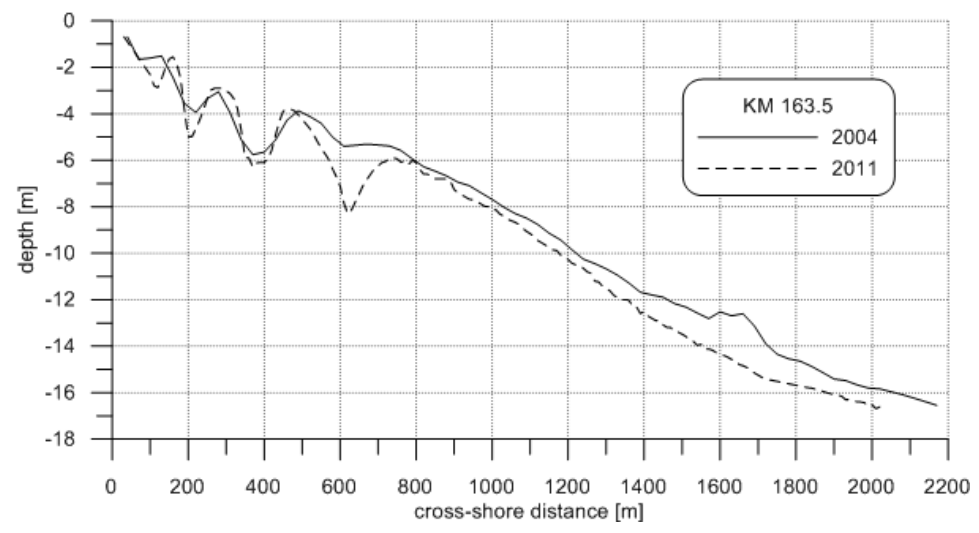

Fig. 3. Cross-shore profile at KM 163.5 in 2004 and in 2011

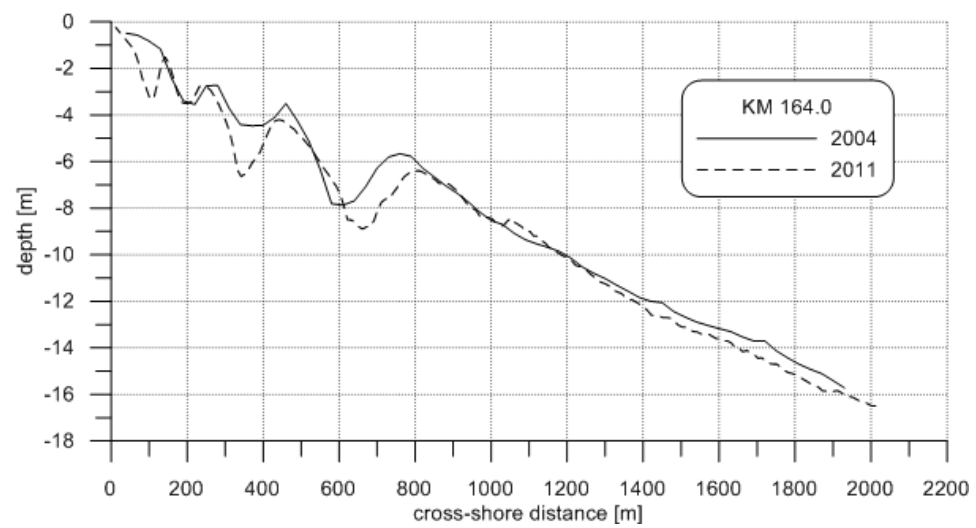

Fig. 4. Cross-shore profile at KM 164.0 in 2004 and in 2011 
considered depend on the needs of projects carried out there, funding opportunities and technical factors (breaks necessary for equipment servicing and conservation, replacement of batteries, etc.). These constraints preclude long-term continuous monitoring of wave parameters.

Since 2001, all offshore wave measurements have been carried out at a location where water depth amounts to 15-18 $\mathrm{m}$, described by the geographical coordinates $54^{\circ} 50^{\prime} \mathrm{N}$ and $17^{\circ} 50^{\prime} \mathrm{E}$, at a distance of $1.0-1.5 \mathrm{Nm}$ (i.e. about $2-3 \mathrm{~km}$ from the shoreline).

\section{Method of Analysis}

The present study continues investigations by Cerkowniak et al (2015), who determined the actual depth of closure $h_{c x}$ from bathymetric surveys carried out at CRS Lubiatowo in 2006-2007 and compared it with $h_{c}$ values calculated from the effective significant wave height $\left(H_{e}\right)$ and period $\left(T_{e}\right)$ by the following formulas, proposed by Hallermeier \& Birkemeier, respectively (see Dean 2002):

$$
\begin{aligned}
& h_{c}=2.28 H_{e}-68.5\left(\frac{H_{e}^{2}}{g T_{e}^{2}}\right), \\
& h_{c}=1.75 H_{e}-57.9\left(\frac{H_{e}^{2}}{g T_{e}^{2}}\right),
\end{aligned}
$$

in which $g$ denotes acceleration due to gravity.

The analysis by Cerkowniak et al (2015) showed that significant changes in the sea bottom $h_{c x}$ took place at depths much greater than $h_{c}=4.9 \mathrm{~m}$, obtained from Eq. (2). These depths were also greater than $h_{c}=6.5 \mathrm{~m}$, yielded by Eq. (1). The value of $h_{x c}$ was smaller than $h_{c}$ (by $0.5 \mathrm{~m}$ ) in one case only. In another specific case, these values were identical $\left(h_{x c}=h_{c}\right)$. With respect to the remaining profiles, the analysis showed that the actual depth of closure $h_{x c}$ was slightly greater (by $19 \%$ at maximum) than the theoretically determined value $\left(_{c}\right)$. It was concluded that the theoretically calculated depth of closure $h_{c}$ was underestimated with respect to the actual $h_{x c}$ values obtained for the multi-bar coastal zone, gradually dissipating wave energy.

It is worth checking whether the motion of sediments at depths greater than the depth of closure values described above is non-existent or very weak. This can be done precisely by determining the sediment transport regime, that is, by determining whether the motion of single grains takes place or intensive transport occurs (up to the sheet flow). For this purpose, the Shields parameter can be employed, which represents the dimensionless bed shear stress and is given by the following formula (see e.g. Nielsen 2009):

$$
\theta=\frac{u_{f}^{2}}{(s-1) g d},
$$


in which $u_{f}=$ the friction velocity, $s=$ the ratio of seabed soil density to water density ( $s=\rho_{s} / \rho$, for quartz sand equal to about 2.65), $g=$ acceleration due to gravity, and $d$ $=$ seabed grain density.

The determination of the friction velocity $u_{f}$ is difficult. The friction velocity represents the bed shear stress $\tau$ (defined as $\tau=\rho u_{f}^{2}$ ), which is the main driving force for sediment transport. According to the basics of fluid mechanics, the bed shear stress $\tau$ depends on the water flow velocity at the top of the bed boundary layer and the sea bottom roughness. The seabed, if built of sandy sediments, becomes moveable under hydrodynamic impacts (resulting from waves and currents), which causes additional difficulties in a theoretical solution leading to the determination of the friction velocity $u_{f}$. In view of the above, according to Nielsen (2009), it is preferable to use a simplified approach which deals with the wave-related bed roughness concerning sand grains only ("skin" bed roughness) and to neglect bed roughness resulting from the presence of bed forms (ripple bed roughness). Such an assumption is justified for a flat bed or weakly developed bottom ripples (sediment motion of small intensity) and for very intensive sediment transport during which the bed forms are washed away (sheet flow). The dimensionless bed shear stress for the situation of "skin" bottom friction, related to a "skin" roughness height of $2.5 d$, can be determined by the following equation (Nielsen 2009):

$$
\theta_{2.5}=\frac{1}{2} f_{2.5} \frac{\left(a_{1 m} \omega\right)^{2}}{(s-1) g d},
$$

in which:

$$
f_{2.5}=\exp \left[5.5\left(\frac{2.5 d}{a_{1 m}}\right)^{0.2}-6.3\right],
$$

where $\omega$ denotes angular frequency in the wave motion, $a_{1 m}=U_{1 m} / \omega$ (amplitude of the nearbed oscillatory flow), and $U_{1 m}$ is the maximum nearbed wave-induced (free stream) oscillatory velocity (for sinusoidal waves, $U(\omega t)=U_{1 m} \sin (\omega t)$ ).

As deduced by Kaczmarek \& Ostrowski $(1995,1996)$, bed shear stresses and sediment transport rates under irregular waves can be successfully modelled with the use of the linear wave theory, taking the root-mean-square wave height $\left(H_{r m s}\right)$ and the wave energy peak period $\left(T_{p}\right)$ as inputs. Therefore, the variables $a_{1 m}$ and $\omega$ (and the related velocity $U_{1 m}$ ) in Eqs. (4) and (5) ought be computed using the wave parameters $H_{r m s}$ and $T_{p}$.

The value $\theta_{2.5}=0.05$ is usually assumed as a condition for the initial motion of single grains. A more intensive motion of seabed grains and developed bottom ripples are observed for $\theta_{2.5}$ equal to $0.2-0.3$. Under considerably intensive hydrodynamic impacts, characterised by $\theta_{2.5}$ amounting to $0.8-1.0$, ripple marks are washed away, and sheet flow occurs.

The calculation of $\theta_{2.5}$ by Eqs. (4) and (5) requires an earlier determination of wave parameters on the cross-shore profile. In the present study, this is done by means of the classical model proposed by Battjes \& Janssen (1978), subsequently adapted for 
a multi-bar cross-shore shape by Szmytkiewicz (1996, 2002a, 2002b). The model is based on the phase-averaged approach. The wave transformation process with a multiple wave breaking can be modelled for an arbitrary angle of deep-water waves. Following Battjes \& Janssen (1978), it is assumed that waves are random and their heights in the entire coastal zone can be described by a Rayleigh distribution. On the basis of experimental investigations and other available data, it may be deduced that this rough assumption can lead to inaccuracies of no more than $10 \%$ in the determination of wave height in the nearshore zone. Assuming that there are no wave reflections from the shore, the wave height is computed from the equation of energy flux conservation, which is a simplified form of the wave action equation. Wave energy dissipation is determined with the assumption that the dissipation is related to the wave breaking process only. Bottom friction, which constitutes the other form of wave energy dissipation, is assumed to be negligibly small, which agrees with experimental assessments by Szmytkiewicz (2002b).

\section{Results and Discussion}

The model was run for the following values of the deep-water significant wave height $H_{s}: 2.5 \mathrm{~m}, 3.0 \mathrm{~m}, 3.5 \mathrm{~m}$ and $3.8 \mathrm{~m}$. The last value corresponds to the long-term (multi-year) effective significant wave height (exceeded for $0.137 \%$ of the time) measured by a wave buoy at CRS Lubiatowo in the periods from September 2006 to September 2007 and (almost continuously) from June 2011 to March 2015. The exceedance percentages for all waves considered are given in Table 1.

Wave transformation on each of the three cross-shore profiles (as they were in both 2004 and 2011) was modelled for each incident wave height $H_{r m s}$. Then, the maximum wave-induced nearbed velocities $U_{1 m}$ and bed shear stresses $\theta_{2.5}$ were calculated along these profiles. Sample results of computations (for the cross-shore profile at KM 164.0 in 2011) are given in Figures 5-8.

In analysing the results of $\theta_{2.5}$ computations, the following regimes of sediment transport were assumed:

$\theta_{2.5} \in<0 ; 0.05>\quad$ no sediment motion;

$\theta_{2.5} \in(0.05 ; 0.3>$ very weak sediment motion, ripples appear on the seabed;

$\theta_{2.5} \in<0.3 ; 0.6>\quad$ weak sediment motion, ripples develop;

$\theta_{2.5} \in<0.6 ; 0.9>$ moderately intensive sediment motion, ripple height decreases;

$\theta_{2.5}>0.9$ intensive sediment motion (sheet flow), flat seabed.

Table 1. Exceedance percentage of time for deep-water significant wave heights $H_{S}$, corresponding root-mean-square wave heights $H_{r m s}$ and wave energy peak periods $T_{p}$ measured at CRS Lubiatowo in 2006-2015

\begin{tabular}{|c|c|c|c|c|}
\hline$H_{s}[\mathrm{~m}]\left(H_{r m s}[\mathrm{~m}]\right)$ & $2.5(1.77)$ & $3.0(2.12)$ & $3.5(2.47)$ & $3.8(2.68)$ \\
\hline$T_{p}[\mathrm{~s}]$ & 7.7 & 8.3 & 9.0 & 9.75 \\
\hline Time exceedance [\%] & 2.07 & 0.83 & 0.33 & 0.137 \\
([hours/year] $)$ & $(181)$ & $(72.77)$ & $(29.25)$ & $(12.0)$ \\
\hline
\end{tabular}




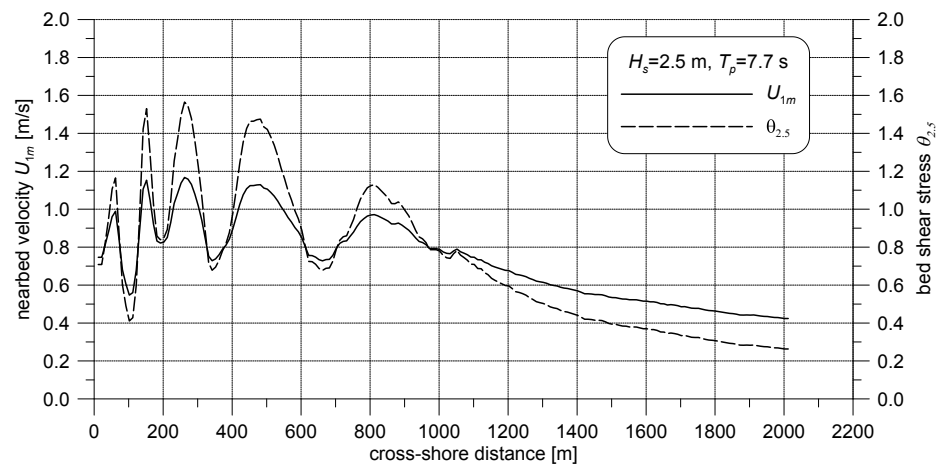

Fig. 5. Wave-induced maximum nearbed velocities $U_{1 m}$ and bed shear stresses $\theta_{2.5}$ modelled for $H_{s}=2.5 \mathrm{~m}$ and $T_{p}=7.7 \mathrm{~s}$ on the cross-shore profile at KM 164.0 (as measured in 2011)

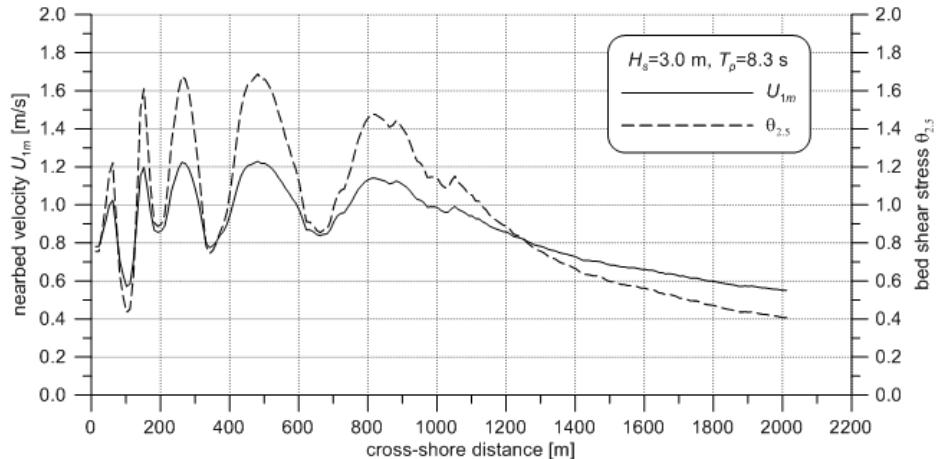

Fig. 6. Wave-induced maximum nearbed velocities $U_{1 m}$ and bed shear stresses $\theta_{2.5}$ modelled for $H_{s}=3.0 \mathrm{~m}$ and $T_{p}=8.3 \mathrm{~s}$ on the cross-shore profile at KM 164.0 (as measured in 2011)

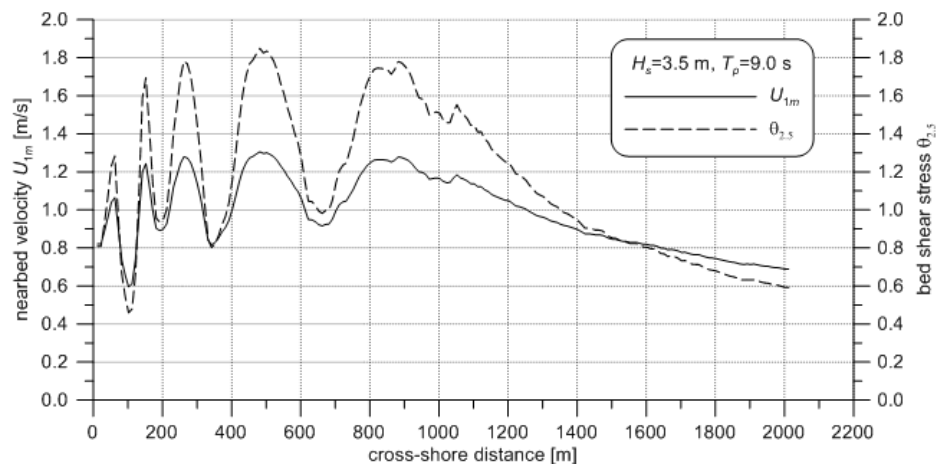

Fig. 7. Wave-induced maximum nearbed velocities $U_{1 \mathrm{~m}}$ and bed shear stresses $\theta_{2.5}$ modelled for $H_{s}=3.5 \mathrm{~m}$ and $T_{p}=9.0 \mathrm{~s}$ on the cross-shore profile at KM 164.0 (as measured in 2011) 


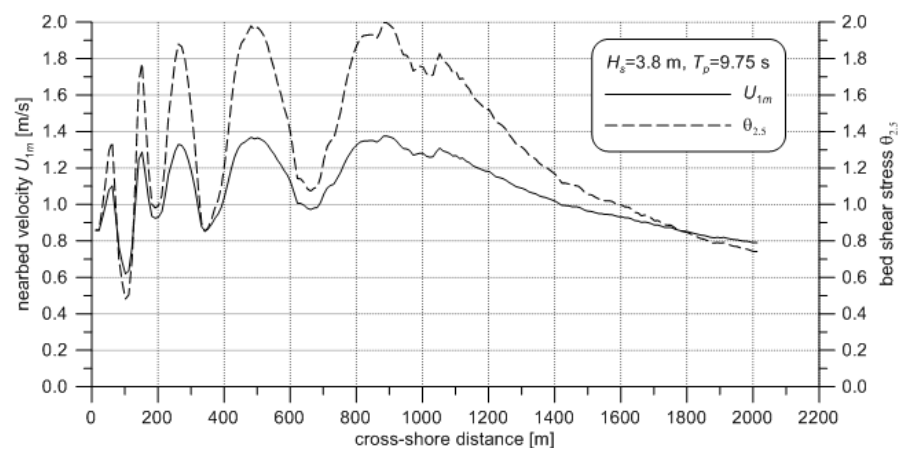

Fig. 8. Wave-induced maximum nearbed velocities $U_{1 m}$ and bed shear stresses $\theta_{2.5}$ modelled for $H_{s}=3.8 \mathrm{~m}$ and $T_{p}=9.75 \mathrm{~s}$ on the cross-shore profile at KM 164.0 (as measured in 2011)

It can be seen in Figures 5 and 6 that the conditions of a typical moderate storm (occurring a few days per year, with $H_{s}=2.5-3.0 \mathrm{~m}$ ) generate high bed shear stresses $\left(\theta_{2.5}>0.9\right)$ and the resulting intensive sediment motion not further than at a distance of about 950-1200 $\mathrm{m}$ from the shoreline, where the water depth amounts to 8-10 $\mathrm{m}$. At greater depths, the values of $\theta_{2.5}$ are much lower, implying weak or very weak sediment transport. Under severe storm conditions (occurring about one day and night per year, $H_{s}=3.5 \mathrm{~m}$, Fig. 7), the zone of high $\theta_{2.5}$ values (and the resulting high sediment transport rates) extends to about 1500-1600 m seawards (to a depth of $h \approx$ $13 \mathrm{~m}$ ), whereas under extreme storm conditions (lasting less than 12 hours per year, $H_{s}=3.8 \mathrm{~m}$, Fig. 8), intensive sediment transport can be expected in regions located even further than $1800 \mathrm{~m}$ offshore, where water depth exceeds $15 \mathrm{~m}$.

The main results of the modelling of sediment transport regimes, namely the depths $h$ and the corresponding distances $x$ from the shoreline where the $\theta_{2.5}$ threshold value of 0.9 occurs for the first time (moving from the deep water towards the shore), together with nearbed wave-induced velocities $U_{1 m}$, are given in Tables 2-5.

The results of numerical modelling shown in Tables 2-5 indicate that intensive sediment transport (sheet flow) occurs if the maximum wave-induced free-stream velocity (of the oscillatory water motion at the top of the bed boundary layer) exceeds $0.85 \mathrm{~m} / \mathrm{s}$. Depending on the severity of storm conditions, this criterion (corresponding to $\theta_{2.5}>0.9$ ) is satisfied at various locations on the cross-shore profile. Even during extreme storms, however, sheet flow is unlikely to happen at water depths greater than $15 \mathrm{~m}$.

Table 2. Locations of the occurrence of $\theta_{2.5}=0.9$ and corresponding velocities $U_{1 \mathrm{~m}}$ for storm conditions with $H_{s}=2.5 \mathrm{~m}$ and $T_{p}=7.7 \mathrm{~s}$

\begin{tabular}{|c|c|c|c|c|c|c|}
\hline Profile & $\begin{array}{c}\text { KM 163.0 } \\
(2004)\end{array}$ & $\begin{array}{c}\text { KM 163.0 } \\
(2011)\end{array}$ & $\begin{array}{c}\text { KM 163.5 } \\
(2004)\end{array}$ & $\begin{array}{c}\text { KM 163.5 } \\
(2011)\end{array}$ & $\begin{array}{c}\text { KM 164.0 } \\
(2004)\end{array}$ & $\begin{array}{c}\text { KM 164.0 } \\
(2011)\end{array}$ \\
\hline$h[\mathrm{~m}]$ & 7.84 & 7.9 & 7.7 & 7.88 & 7.74 & 7.94 \\
\hline$x[\mathrm{~m}]$ & 950 & 936 & 1000 & 970 & 940 & 942 \\
\hline$U_{1 m}[\mathrm{~m} / \mathrm{s}]$ & 0.84 & 0.83 & 0.85 & 0.84 & 0.85 & 0.83 \\
\hline
\end{tabular}


Table 3. Locations of the occurrence of $\theta_{2.5}=0.9$ and corresponding velocities $U_{1 \mathrm{~m}}$ for storm conditions with $H_{s}=3.0 \mathrm{~m}$ and $T_{p}=8.3 \mathrm{~s}$

\begin{tabular}{|c|c|c|c|c|c|c|}
\hline Profile & $\begin{array}{c}\text { KM 163.0 } \\
(2004)\end{array}$ & $\begin{array}{c}\text { KM 163.0 } \\
(2011)\end{array}$ & $\begin{array}{c}\text { KM 163.5 } \\
(2004)\end{array}$ & $\begin{array}{c}\text { KM 163.5 } \\
(2011)\end{array}$ & $\begin{array}{c}\text { KM 164.0 } \\
(2004)\end{array}$ & $\begin{array}{c}\text { KM 164.0 } \\
(2011)\end{array}$ \\
\hline$h[\mathrm{~m}]$ & 10.36 & 10.38 & 10.25 & 10.26 & 10.14 & 10.24 \\
\hline$x[\mathrm{~m}]$ & 1220 & 1186 & 1240 & 1200 & 1210 & 1212 \\
\hline$U_{1 m}[\mathrm{~m} / \mathrm{s}]$ & 0.84 & 0.84 & 0.85 & 0.85 & 0.85 & 0.85 \\
\hline
\end{tabular}

Table 4. Locations of the occurrence of $\theta_{2.5}=0.9$ and corresponding velocities $U_{1 m}$ for storm conditions with $H_{s}=3.5 \mathrm{~m}$ and $T_{p}=9.0 \mathrm{~s}$

\begin{tabular}{|c|c|c|c|c|c|c|}
\hline Profile & $\begin{array}{c}\text { KM 163.0 } \\
(2004)\end{array}$ & $\begin{array}{c}\text { KM 163.0 } \\
(2011)\end{array}$ & $\begin{array}{c}\text { KM 163.5 } \\
(2004)\end{array}$ & $\begin{array}{c}\text { KM 163.5 } \\
(2011)\end{array}$ & $\begin{array}{c}\text { KM 164.0 } \\
(2004)\end{array}$ & $\begin{array}{c}\text { KM 164.0 } \\
(2011)\end{array}$ \\
\hline$h[\mathrm{~m}]$ & 12.8 & 13.11 & 12.6 & 13.1 & 13 & 13.11 \\
\hline$x[\mathrm{~m}]$ & 1610 & 1476 & 1660 & 1450 & 1570 & 1512 \\
\hline$U_{1 m}[\mathrm{~m} / \mathrm{s}]$ & 0.86 & 0.85 & 0.87 & 0.85 & 0.85 & 0.85 \\
\hline
\end{tabular}

Table 5. Locations of the occurrence of $\theta_{2.5}=0.9$ and corresponding velocities $U_{1 m}$ for storm conditions with $H_{s}=3.8 \mathrm{~m}$ and $T_{p}=9.75 \mathrm{~s}$

\begin{tabular}{|c|c|c|c|c|c|c|}
\hline Profile & $\begin{array}{c}\text { KM 163.0 } \\
(2004)\end{array}$ & $\begin{array}{c}\text { KM 163.0 } \\
(2011)\end{array}$ & $\begin{array}{c}\text { KM 163.5 } \\
(2004)\end{array}$ & $\begin{array}{c}\text { KM 163.5 } \\
(2011)\end{array}$ & $\begin{array}{c}\text { KM 164.0 } \\
(2004)\end{array}$ & $\begin{array}{c}\text { KM 164.0 } \\
(2011)\end{array}$ \\
\hline$h[\mathrm{~m}]$ & 14.78 & 15.10 & 14.86 & 15.05 & 14.92 & 15.10 \\
\hline$x[\mathrm{~m}]$ & 1820 & 1766 & 1840 & 1680 & 1840 & 1792 \\
\hline$U_{1 m}[\mathrm{~m} / \mathrm{s}]$ & 0.87 & 0.85 & 0.87 & 0.86 & 0.86 & 0.85 \\
\hline
\end{tabular}

\section{Final Remarks and Conclusions}

For the site considered, according to Cerkowniak et al (2015), the offshore boundary of intensive wave-induced sediment transport, defined by the depth of closure $h_{c}$ assessed from bathymetric surveys, lies at a depth of 6.0-7.7 m. In particular, the values of $h_{c}$ amount to $6 \mathrm{~m}$ and $7.5 \mathrm{~m}$ for two IBW PAN cross-shore profiles corresponding to the transects at KM 163.5 and KM 164, respectively (the transect at KM 163 lies beyond the longshore span of the bathymetric surveys conducted at CRS Lubiatowo). The value $h_{c}=7.5 \mathrm{~m}$ seems to be in agreement with the data presented in Fig. 4 (KM 164), whereas the value $h_{c}=6 \mathrm{~m}$ is not confirmed by the bathymetric data plotted in Fig. 3 (KM 163.5). One cannot be sure, however, whether the spatial repeatability of the bathymetric surveys was satisfied in measurements on this transect. This uncertainty also concerns the profile at KM 163 (Fig. 2). Undoubtedly, the positioning of the measuring boat (and echo-sounding itself) was much more accurate in 2011 than in 2004. On the other hand, deep-water morphodynamic processes, manifesting themselves by sea bottom evolution and the disappearance of large bed forms at distances of 1500-1700 $\mathrm{m}$ from the shoreline (see Figures 2 and 3), may have actually occurred.

The values of $h_{c}$ for the Lubiatowo region obtained by Cerkowniak et al (2015) using Eq. (1) and Eq. (2) were equal to $6.5 \mathrm{~m}$ and $4.9 \mathrm{~m}$, respectively. In view of the results of the bathymetric surveys, the latter figure (determined by Birkemeier's 
formula) seems distinctly underestimated. The values of $h_{c}$ assessed from the bathymetric surveys were also generally greater than $6.5 \mathrm{~m}$ (calculated by Hallermeier's formula). As pointed out by Dean (2002), semi-empirical formulas for the determination of the depth of closure $h_{c}$, i.e. Equations (1) and (2), have been derived with the assumption that the bed shear stresses generated by nearbed wave-induced oscillatory flows are the driving force for sediment transport. It is possible, however, that nearbed wave-driven oscillations at depths greater than 6-7 m interact with sea currents, such as wind drift or gradient currents. It can be expected that such currents, superimposed on wave-induced water flow, cause a considerable increase in the bed shear stress, so that sediment motion begins, which would not take place if the seabed was affected by wave-induced currents only.

The investigations carried out for the multi-bar shore, characteristic of the south Baltic Sea, show that the wave-induced bed shear stresses during heavy storms (with the deep water significant wave height $H_{s}$ exceeding $3.5 \mathrm{~m}$ ) can cause intensive sediment transport even at depths of 13-15 m. Such wave conditions, however, last no longer than one day and night per year. Can they, by themselves, cause the appearance and movement of large offshore bed forms, similar to bars? Or can these forms appear and evolve at large depths only if stormy waves are accompanied by strong sea currents?

The above considerations give rise to a hypothesis about an important role of currents typically occurring beyond the surf zone and interacting with wave-induced oscillatory flows. Under storm conditions, this interaction presumably generates bed shear stresses sufficient to cause intensive sediment transport and, consequently, distinct sea bottom evolution.

It is therefore worthwhile to continue research on the offshore boundary of the range of seabed changes in various time scales. Further activities related to this topic will be aimed at a precise determination of the sediment motion driving forces (bed shear stresses) resulting from the interaction of nearbed wave-induced oscillations (orbital velocities) with steady currents observed at the seaward boundary of the surf zone and beyond the surf zone.

Flow velocities in the bed boundary layer of the Baltic Sea beyond the surf zone have never been measured. Such measurements, together with thorough observations of seabed changes, would shed new light on the nearbed hydro- and lithodynamics in a transitional region between the surf zone and the deep sea.

\section{Acknowledgements}

The study was sponsored by the Ministry of Science and Higher Education, Poland under mission-related programme No. 2 of IBW PAN and the research project No. 2012/05/B/ST10/00926 (Analysis of impact of wind and infragravity waves on coastal and seabed evolution - extension and verification of mathematical and numerical models). The Authors wish to thank the Maritime Office in Gdynia (Inspectorate of 
Coastal Protection) for provision of the coastal bathymetric data. We are grateful to Professor Zbigniew Pruszak for his helpful comments on an earlier version of this manuscript.

\section{References}

Battjes J. A., Janssen J. P. F. M. (1978) Energy loss and set-up due to breaking of random waves, Proc. $16^{\text {th }}$ ICCE, I, 569-587.

Beavers R., Howd P., Birkemeier W., Hathaway K. (1999) Evaluating profile data and depth of closure with Sonar Altimetry, Proc. Coastal Sediments'99, Hauppauge (Long Island), ASCE, 479-490.

Birkemeier W. A. (1985) Field data on seaward limit of profile change, Journal of Waterway, Port, Coastal and Ocean Engineering, 111, (3), 598-602.

Capobianco M., Larson M., Nicholls J., Kraus N. (1997) Depth of closure. A contribution to the reconciliation of theory, practice and evidence, Proc. Costal Dynamics'97, Plymouth, ASCE, 506-515.

Carbajal N., Montaño Y. (2001) Comparison between Predicted and Observed Physical Features of Sandbanks, Estuarine, Coastal and Shelf Science, (52), 435-443.

Cerkowniak G. R., Ostrowski R., Pruszak Z., Skaja M., Stella M. (2015) Closure depth theory in view of field measurements on the multi-bar sea shore, Inżynieria Morska i Geotechnika, (1), 10-17 (in Polish).

Dean R. G. (2002) Beach Nourishment. Theory and Practice. Advanced Series on Ocean Engineering - Volume 18, World Scientific Publishing Co. Pte. Ltd., 399 pp.

Hallermeier R. J. (1978) Uses for a calculated limit depth to beach erosion, Proceedings $16^{\text {th }}$ Coastal Engineering Conference, American Society of Civil Engineers, 1493-1512.

Hallermeier R. J. (1981) A profile zonation for seasonal sand beaches from wave climate, Coastal Engineering, (4), 253-277.

Hulscher S. J. M. H., van den Brink G. M. (2001) Comparison between predicted and observed sand waves and sand banks in the North Sea, Journal of Geophysical Research, 106, (C5), 9327-9338.

Kaczmarek L. M., Ostrowski R. (1995) Modelling of Bed Shear Stress under Irregular Waves, Archives of Hydro-Engineering and Environmental Mechanics, 42, (1-2), 29-51.

Kaczmarek L. M., Ostrowski R. (1996) Bedload Under Asymmetric and Irregular Waves: Theory Versus Laboratory Data, Archives of Hydro-Engineering and Environmental Mechanics, 43, (1-4), 21-42.

Nicholls R., Birkemeier W., Hallermeier R. (1996) Application of depth of closure concept, Proc. $25^{\text {th }}$ International Conf. on Coastal Engineering, Orlando, ASCE, 3874-3887.

Nicholls R., Birkemeier W. (1997) Morphological and sediment budget controls on depth of closure at Duck, NC, Proc. Coastal Dynamics'97, Plymouth, ASCE, 496-505.

Nielsen P. (2009) Coastal and Estuarine Processes, Advanced Series on Ocean Engineering - Volume 29, World Scientific Publishing Co. Pte. Ltd., 343 pp.

Pruszak Z., Szmytkiewicz P., Ostrowski R., Skaja M., Szmytkiewicz M. (2008) Shallow-water wave energy dissipation in a multi-bar coastal zone, Oceanologia, 50, (1), 43-58.

Różyński G., Pruszak Z., Okrój T., Zeidler R. (1998) Depth of closure and seabed variability patterns, Proc. $26^{\text {th }}$ International Conf. on Coastal Engineering, Copenhagen, ASCE, 2926-2939.

Szmytkiewicz M. (1996) 2D velocity distributions in nearshore currents, Proc. Coastal Dynamics '95, ASCE, 366-376.

Szmytkiewicz M. (2002a) Wave-induced currents in the coastal zone, IBW PAN Publishers, Gdańsk, ISBN 83-85708-45-6, 235 pp. (in Polish).

Szmytkiewicz M. (2002b) Quasi 3D model of wave-induced currents in coastal zone, Archives of Hydro-Engineering \& Environmental Mechanics, 49, (1), 57-81. 